\title{
UNSTEADY FLOW IN A SUPERSONIC TURBINE WITH VARIABLE SPECIFIC HEATS
}

\author{
Daniel J. Dorney* Lisa W. Griffin ${ }^{\dagger}$ \\ Applied Fluids Dynamic Analysis Branch \\ NASA Marshall Space Flight Center \\ Marshall Space Flight Center, Alabama, 35812, USA
}

\author{
Frank Huber ${ }^{\ddagger}$ \\ Riverbend Design Services \\ Palm Beach Gardens, Florida, 33418, USA
}

\author{
Douglas L. Sondak ${ }^{\S}$ \\ Office of Information Technology \\ Boston University \\ Boston, MA, 02215, USA
}

\section{INTRODUCTION}

Modern high-work turbines can be compact, transonic, supersonic, counter-rotating, or use a dense drive gas. The vast majority of modern rocket turbine designs fall into these categories. These turbines usually have large temperature variations across a given stage, and are characterized by large amounts of flow unsteadiness. The flow unsteadiness can have a major impact on the turbine performance and durability. For example, the Space Transportation

*Aerospace Engineer, Senior Member AIAA

†Team Leader, Senior Member AIAA

tPresident, Senior member AIAA

§Senior Scientific Programmer, Senior Member AIAA.

Copyright (C) 2001 by the American Institute of Aeronautics and Astronautics, Inc. No copyright is asserted in the United States under Title 17, U.S. Code. The U.S. Government has a royalty-free license to exercise all rights under the copyright claimed herein for Governmental Purposes. All other rights are reserved by the copyright owner. 
Main Engine (STME) fuel turbine, a high work, transonic design, was found to have an unsteady inter-row shock which reduced efficiency by 2 points and increased dynamic loading by 24 percent. The Revolutionary Reusable Technology Turbopump (RRTT), which uses full flow oxygen for its drive gas, was found to shed vortices with such energy as to raise serious blade durability concerns. In both cases, the sources of the problems were uncovered (before turbopump.testing) with the application of validated, unsteady computational fluid dynamics (CFD) to the designs. In the case of the RRTT and the Alternate Turbopump Development (ATD) turbines, the unsteady CFD codes have been used not just to identify problems, but to guide designs which mitigate problems due to unsteadiness. Using unsteady flow analyses as a part of the design process has led to turbine designs with higher performance (which affects temperature and mass flow rate) and fewer dynamics problems. The works of Griffin et al. [1], Garcia et al. [2] and Griffin and Dorney [3] are examples of the application of unsteady CFD to rocket turbine designs.

One of the many assumptions made during the design and analysis of supersonic turbine stages is that the values of the specific heats are constant. In some analyses the value is based on an average of the expected upstream and downstream temperatures. In stages where the temperature can vary by 300 to $500^{\circ} \mathrm{K}$, however, the assumption of constant fluid properties may lead to erroneous performance and durability predictions. In this study the suitability of assuming constant specific heats has been investigated by performing three-dimensional unsteady Navier-Stokes simulations for a supersonic turbine stage. In the first simulation the fluid properties were held constant, while in the second simulation the specific heats were allowed to vary locally as a function of static temperature. The predicted results from both simulations have been compared to the results of a well-validated meanline analysis which was also modified for variable specific heats. The meanline analysis is composed of one-dimensional equations of motion and empirical correlations.

\section{NUMERICAL ALGORITHM}

The governing equations considered in this study are the time dependent, three-dimensional Reynolds-averaged Navier-Stokes equations. To extend the equations of motion to turbulent flows, an eddy viscosity formulation is used. The turbulent viscosity is calculated using a two-layer algebraic turbulence model. The numerical algorithm consists of a time-marching, implicit, finite-difference scheme. The procedure is third-order spatially accurate and second- 
order temporally accurate. The inviscid fluxes are discretized using a third-order upwindbiased scheme, while the viscous fluxes are calculated using standard central differences. An approximate-factorization technique is used to compute the time rate changes in the conserved variables. The numerical analysis uses Message Passing Interface (MPI) to reduce the computation time for large-scale three-dimensional simulations.

The Navier-Stokes analysis uses $\mathrm{O}$ - and H-type zonal grids to discretize the flow field and facilitate relative motion of the rotating components. The O-grids are body-fitted to the surfaces of the airfoils and generated using an elliptic equation solution procedure. They are used to properly resolve the viscous flow in the blade passages and to easily apply the algebraic turbulence model. The algebraically-generated H-grids are used to discretize the remainder of the flow field.

The computational analysis has been validated on several supersonic turbine geometries (e.g., Refs. [3] and [4]).

\section{GEOMETRY AND GRIDS}

The supersonic turbine configuration, typical of those proposed for a reusable launch vehicle, consists of 21 vane airfoils and 52 rotor blades. In the current effort a 2 -vane/5-rotor blade count approximation has been made. To keep the pitch-to-chord ratio constant, the vane airfoils were scaled by factor of $21 / 20$ and the rotor blades were scaled by a factor of $52 / 50$. The rotor tip clearance was set at a typical value of approximately $2.5 \%$ of the rotor height. Two simulations have been performed for the turbine, one with constant specific heats (Case 1) and one in which the specific heats vary as a function of temperature (Case 2).

The grid dimensions (number of passages $\times \mathbf{i} \times \mathbf{j} \times \mathrm{k}$ ) for the turbine simulations are presented in Table 1. Previous simulations suggested that 38 spanwise planes are adequate to resolve the predominant flow features for this type of geometry [3]. Figure 1 illustrates the midspan section of the computational grids. The total number of grid points used to discretize the turbine was $1,363,022$. The average value of $y^{+}$, the non-dimensional distance of the first grid line above the surface was approximately 1.5 for the airfoil surfaces and 3.5 for the endwalls.

The simulations were run on seven $250 \mathrm{MHz}$ processors of an SGI Origin2000. Each simulation was run for 12.5 global cycles (in excess of one complete rotor revolution) at 25,000 iterations per cycle, where a global cycle is defined as the time it takes for the five rotor blades to pass the two vane airfoils. The value of 25,000 iterations per cycle was chosen to resolve 
all the expected frequencies of interest. Each iteration required approximately 16 seconds computation time on seven processors. The time periodicity of the solutions was determined by plotting pressure traces at different points along the airfoil surfaces.

\section{NUMERICAL RESULTS}

The turbine under consideration has an inlet Mach number of $M_{0}=0.12$, an inlet static pressure of $15.2 \mathrm{MPa}$, and an inlet static temperature of $T_{0}=1232 \mathrm{~K}$. The rotor rotates at $\Omega=31,300 \mathrm{RPM}$, the Reynolds number (based on the inlet conditions and the rotor axial chord) is approximately $5 \times 10^{5}$ and the ratio of the rotor exit static pressure to vane inlet total pressure is $P_{2} / P_{t 0}=0.1875$. The operating fluid in the turbine is a gaseous hydrogen mixture. In Case 1 a constant specific heat ratio of $\gamma=1.354$ was assumed, while in Case 2 the specific heat ratio was varied locally according to the following equations:

$$
\begin{gathered}
\gamma=\frac{C_{p} / R}{\left(C_{p} / R\right)-1} \\
C_{p} / R=a_{1}+a_{2} * T+a_{3} * T^{2}+a_{4} * T^{3}+a_{5} * T^{4}
\end{gathered}
$$

where the coefficients for hydrogen are [5]:

$$
\begin{aligned}
& a_{1}=0.39508691 E+01 \\
& a_{2}=0.10207987 E+00 \\
& a_{3}=0.13124466 E-04 \\
& a_{4}=-0.76649284 E-07 \\
& a_{5}=0.34503763 E-10
\end{aligned}
$$

for temperatures between 300 and $1000 \mathrm{~K}$, and

$$
\begin{aligned}
& a_{1}=0.36440206 E+02 \\
& a_{2}=0.54614801 E-01 \\
& a_{3}=-0.16091151 E-04 \\
& a_{4}=0.21478497 E-08 \\
& a_{5}=-0.10131180 E-12
\end{aligned}
$$

for temperatures between 1000 and $5000 \mathrm{~K}$. The addition of the subroutine to calculate the local values of the specific heats resulted in less than a $5 \%$ increase in CPU time.

Tables 2 and 3 contain time mean of the mass-averaged relative frame flow quantities predicted by the Navier-Stokes simulation and meanline analysis for the constant and variable flow property simulations, respectively. The values presented for the Navier-Stokes simulations were time- and mass-averaged at the computational inlet (located approximately one 
axial chord upstream of the vane leading edge), midway between the vane trailing edge and rotor leading edge and at the computational exit (approximately 1.25 axial chord lengths downstream of the rotor trailing edge).

In general, the results from the Navier-Stokes and meanline analyses display good agreement in the vane passage, but exhibit differences in the rotor passage (see Tables 2 and 3). The meanline analysis predicts more flow turning and higher rotor exit relative Mach numbers, while the Navier-Stokes analysis predicts higher losses (associated with the endwall and tip gap flows). The differences between the meanline and Navier-Stokes solutions for the rotor are not surprising because the meanline code relies on empirical loss models for which there are limited data for supersonic turbomachinery flows. The total-to-total efficiencies predicted by the two analyses show fair agreement, whereas the predicted total-to-static efficiencies and work are in excellent agreement.

Comparing the constant and variable fluid property data, the meanline results indicate insignificant changes in both the total-to-total and total-to-static efficiencies, while the NavierStokes analysis predicts a small decrease in the efficiencies. Both analyses predict a slight decrease in the work extracted by the turbine for variable specific heats.

Time-averaged pressure distributions for the vane and rotor at 10\%, 50\% and 90\% span are shown in Figs. 2 and 3, respectively. The vane loadings in both simulations are similar on the pressure surface and upstream of the throat on the suction surface. Downstream of the throat the case with variable fluid properties displays slightly lower pressures (which agrees with the Mach numbers in Tables 2 and 3) and increased loading. The results from Case 2 indicate slightly more loading and higher pressures on the rotor at $50 \%$ and $90 \%$ span, while the loadings are similar at $10 \%$ span although the pressures are significantly lower in Case 2. The differences at $10 \%$ span suggest the nature of the flow in the hub region may be altered by the variable specific heats.

Figures 4 and 5 illustrate a comparison of unsteady pressure traces near the leading edge of the rotor at $10 \%$ and $50 \%$ span, respectively. While the pressure traces between $25 \%$ and $75 \%$ span were similar in both simulations, there were significant differences (in both magnitude and frequency content) at $10 \%$ and $90 \%$ span (i.e., in the endwall regions). Interrogation of the frequency spectrum associated with the unsteadiness at the $10 \%$ span location of the rotor (obtained via Fourier decompositions of the unsteady pressure traces) reveals that Case 2 contains significantly more unsteadiness at the vane passing frequency (approximately 10,000 
$\mathrm{Hz}$ ), as well as increased unsteadiness below and above the vane passing frequency (see Fig. 6). In Fig. 6 the frequencies for Case 2 were offset by $500 \mathrm{~Hz}$ to facilitate comparisons with Case 1. In an effort to determine if the differences in the unsteady pressures at $10 \%$ span are confined to the leading edge of the rotor, additional traces were compared on both the suction and pressure surfaces. The traces showed similar behavior to the one near the leading edge. Thus, the unsteady pressures appear to be different in regions normally associated with strong secondary flows.

\section{CONCLUSIONS}

A set of unsteady three-dimensional Navier-Stokes simulations has been used to investigate the effects of varying specific heats on the performance of a supersonic turbine stage. One simulation was performed assuming constant specific heats, while one was performed in which the specific heats varied locally as a function of the static temperature. The results of both simulations have been compared with the output from meanline simulations.

The flow quantities predicted by the meanline and Navier-Stokes analyses (for both constant and variable flow properties) show good agreement at the exit of the vane, but exhibit significant differences at the rotor exit (which is to be expected because of the lack of data and correlations available for supersonic turbines). There is excellent agreement between the total-to-static efficiencies and work predicted by both analyses.

The Navier-Stokes results indicate increased pressure unsteadiness in the endwall regions for variable specific heats. In addition, the losses increased and the efficiencies decreased in the variable fluid property simulation. The meanline analysis predicted little change in the efficiencies for variable fluid properties, but similar to the Navier-Stokes results indicates reduced work. Thus, the current results indicate that it is important to include the effects of variable specific heats.

\section{References}

[1] Griffin, L. W., Huber, F. W., and Sharma, O. P., "Performance Improvement Through Indexing of Turbine Airfoils: Part 2: Numerical Simulation", ASME Journal of Turbomachinery, Vol. 118, No. 4, 1996, pp. 636-642. 
[2] Garcia, R., Griffin, L. W., Benjamin, T. G., Cornelison, J. W., Ruf, J. H., and Williams, R. W., "Computational Fluid Dynamics Analysis in Support of the Simplex Turbopump Design", NASA CP-3282 Vol. 1, 1995, pp. 462-470.

[3] Griffin, L. W. and Dorney, D. J., "Simulations of the Unsteady Flow Through the Fastrac Supersonic Turbine," ASME Journal of Turbomachinery, Vol. 122, No. 2, April, 2000, qpp. 225-233

[4] Dorney, D. J., Griffin, L. W., and Huber, F., "A Study of the Effects of Tip Clearance in a Supersonic Turbine," ASME Journal of Turbomachinery, Vol. 122, No. 4, October, 2000, pp. 674-673.

[5] Wang, T.-S., "Thermophysics Characterization of Kerosene Combustion," AIAA Journal of Thermophysics and Heat Transfer, Vol. 15, No. 2, April-June, 2001, pp. 140-147. 
Table 1. Computational grid dimensions.

Table 2. Case 1 time-averaged relative reference frame flow quantities.

Table 3. Case 2 time-averaged relative reference frame flow quantities.

Figure 1. Midspan section of turbine grid.

Figure 2. Time-averaged pressure - vane; - Case 1, - - Case 2.

Figure 3. Time-averaged pressure - rotor; - C Case 1, - - Case 2.

Figure 4. Pressure history - rotor - 10\% span - near leading edge; — Case 1, - - Case 2.

Figure 5. Pressure history - rotor - 50\% span - near leading edge; - Case 1, - - Case 2.

Figure 6. Pressure decomposition - rotor - $10 \%$ span - near leading edge; - Case 1, - Case 2. 


\begin{tabular}{|l|l|l|}
\hline \hline Grid Type & Vane & Rotor \\
\hline $\mathrm{O}$ & $2 \times 121 \times 31 \times 38$ & $5 \times 121 \times 21 \times 38$ \\
$\mathrm{H}$ & $2 \times 86 \times 41 \times 38$ & $5 \times 82 \times 21 \times 38$ \\
Tip & - & $5 \times 121 \times 16 \times 5$ \\
\hline Total Points & 553,052 & 858,370 \\
\hline
\end{tabular}

Table 1: 


\begin{tabular}{|l|l|l|l|l|}
\hline & \multicolumn{2}{|c|}{ Navier-Stokes } & \multicolumn{2}{c|}{ Meanline } \\
\hline Variable & Vane & Rotor & Vane & Rotor \\
\hline$M_{\text {in }}$ & 0.12 & 1.15 & 0.12 & 1.22 \\
\hline$M_{\text {out }}$ & 1.42 & 1.12 & 1.52 & 1.30 \\
\hline$P_{\text {in }}(\mathrm{MPa})$ & 15.2 & 4.20 & 15.2 & 3.87 \\
\hline$P_{\text {out }}(\mathrm{Mpa})$ & 4.20 & 2.89 & 3.87 & 2.89 \\
\hline$H t_{\text {in }}(\mathrm{kJ} / \mathrm{kg})$ & 1787 & 1622 & 1787 & 1619 \\
\hline$H t_{\text {out }}(\mathrm{kJ} / \mathrm{kg})$ & 1786 & 1614 & 1787 & 1619 \\
\hline$P t_{\text {in }}(\mathrm{MPa})$ & 15.4 & 9.49 & 15.4 & 9.44 \\
\hline$P t_{\text {out }}(\mathrm{MPa})$ & 13.7 & 6.36 & 13.8 & 7.92 \\
\hline$\beta_{\text {in }}(\mathrm{deg})$ & 0.0 & 63.7 & 0.0 & 72.1 \\
\hline$\beta_{\text {out }}(\mathrm{deg})$ & 73.3 & -61.6 & 73.8 & -70.5 \\
\hline$\gamma$ & 1.354 & 1.354 & 1.354 & 1.354 \\
\hline Reaction & - & 0.095 & - & 0.073 \\
\hline$W(\mathrm{KJ} / \mathrm{kg})$ & - & 284.3 & - & 285.0 \\
\hline$\eta_{t t}$ & - & 0.608 & - & 0.635 \\
\hline$\eta_{t s}$ & - & 0.449 & - & 0.450 \\
\hline \hline
\end{tabular}

Table 2: 


\begin{tabular}{|l|l|l|l|l|}
\hline \hline & \multicolumn{2}{|l|}{ Navier-Stokes } & \multicolumn{2}{c|}{ Meanline } \\
\hline Variable & Vane & Rotor & Vane & Rotor \\
\hline$M_{\text {in }}$ & 0.12 & 1.16 & 0.12 & 1.21 \\
\hline$M_{\text {out }}$ & 1.42 & 1.10 & 1.51 & 1.31 \\
\hline$P_{\text {in }}(\mathrm{MPa})$ & 15.2 & 4.20 & 15.2 & 3.90 \\
\hline$P_{\text {out }}(\mathrm{Mpa})$ & 4.20 & 2.89 & 3.90 & 2.89 \\
\hline$H t_{\text {in }}(\mathrm{kJ} / \mathrm{kg})$ & 1787 & 1629 & 1776 & 1512 \\
\hline$H t_{\text {out }}(\mathrm{kJ} / \mathrm{kg})$ & 1786 & 1617 & 1776 & 1512 \\
\hline$P t_{\text {in }}(\mathrm{MPa})$ & 15.4 & 9.36 & 15.4 & 9.51 \\
\hline$P t_{\text {out }}(\mathrm{MPa})$ & 13.4 & 6.29 & 13.9 & 8.05 \\
\hline$\beta_{\text {in }}(\mathrm{deg})$ & 0.0 & 63.6 & 0.0 & 72.5 \\
\hline$\beta_{\text {out }}(\mathrm{deg})$ & 73.1 & -62.0 & 74.2 & -71.1 \\
\hline$\gamma_{\text {in }}$ & 1.363 & 1.380 & 1.357 & 1.383 \\
\hline$\gamma_{\text {out }}$ & 1.380 & 1.381 & 1.383 & 1.386 \\
\hline Reaction & - & 0.092 & - & 0.082 \\
\hline$W(\mathrm{KJ} / \mathrm{kg})$ & - & 282.0 & - & 284.7 \\
\hline$\eta_{\text {tt }}$ & - & 0.602 & - & 0.634 \\
\hline$\eta_{\text {ts }}$ & - & 0.447 & - & 0.450 \\
\hline \multicolumn{5}{|l}{} \\
\hline
\end{tabular}

Table 3: 




Figure 1: 

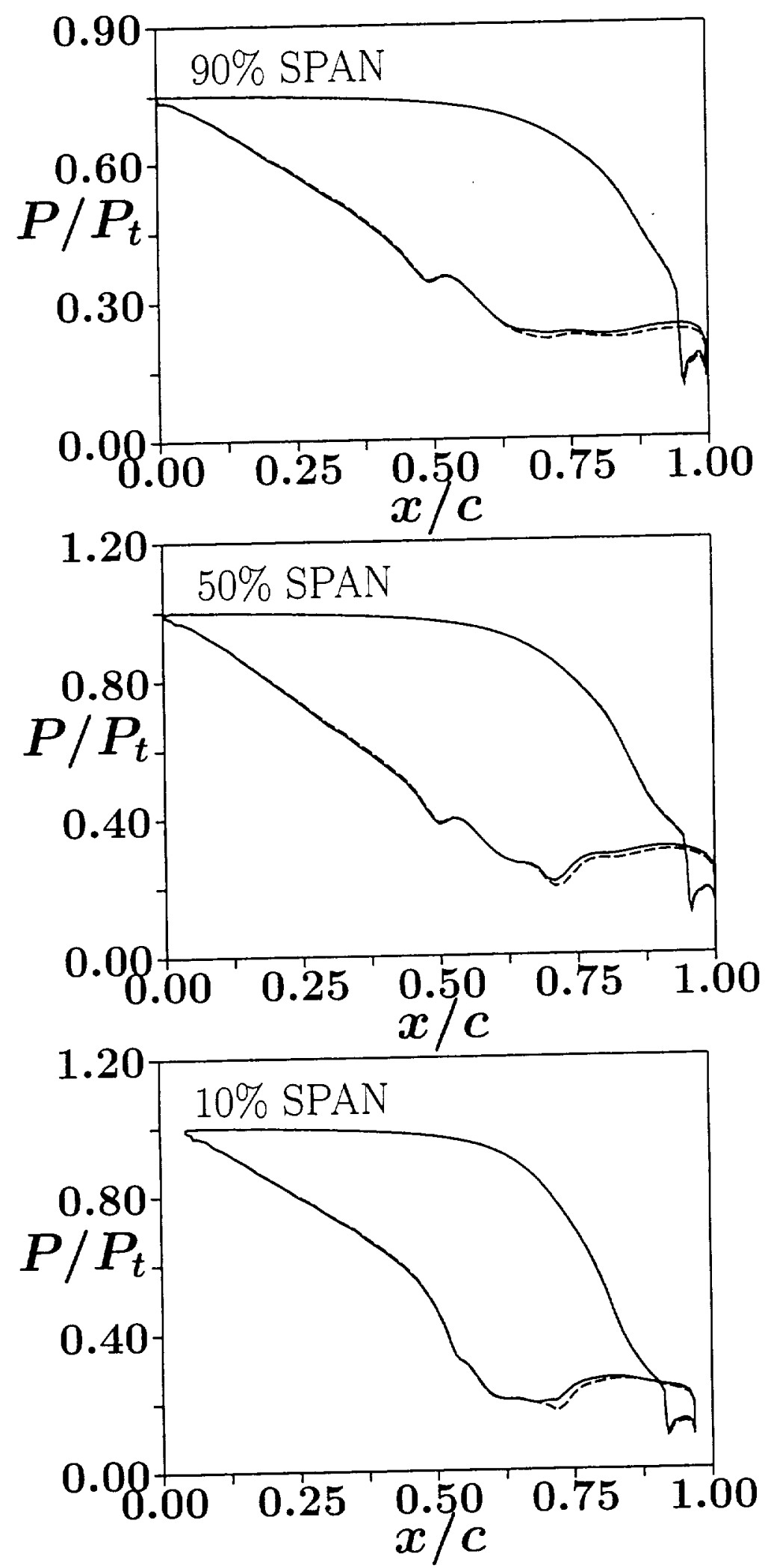

Figure 2: 

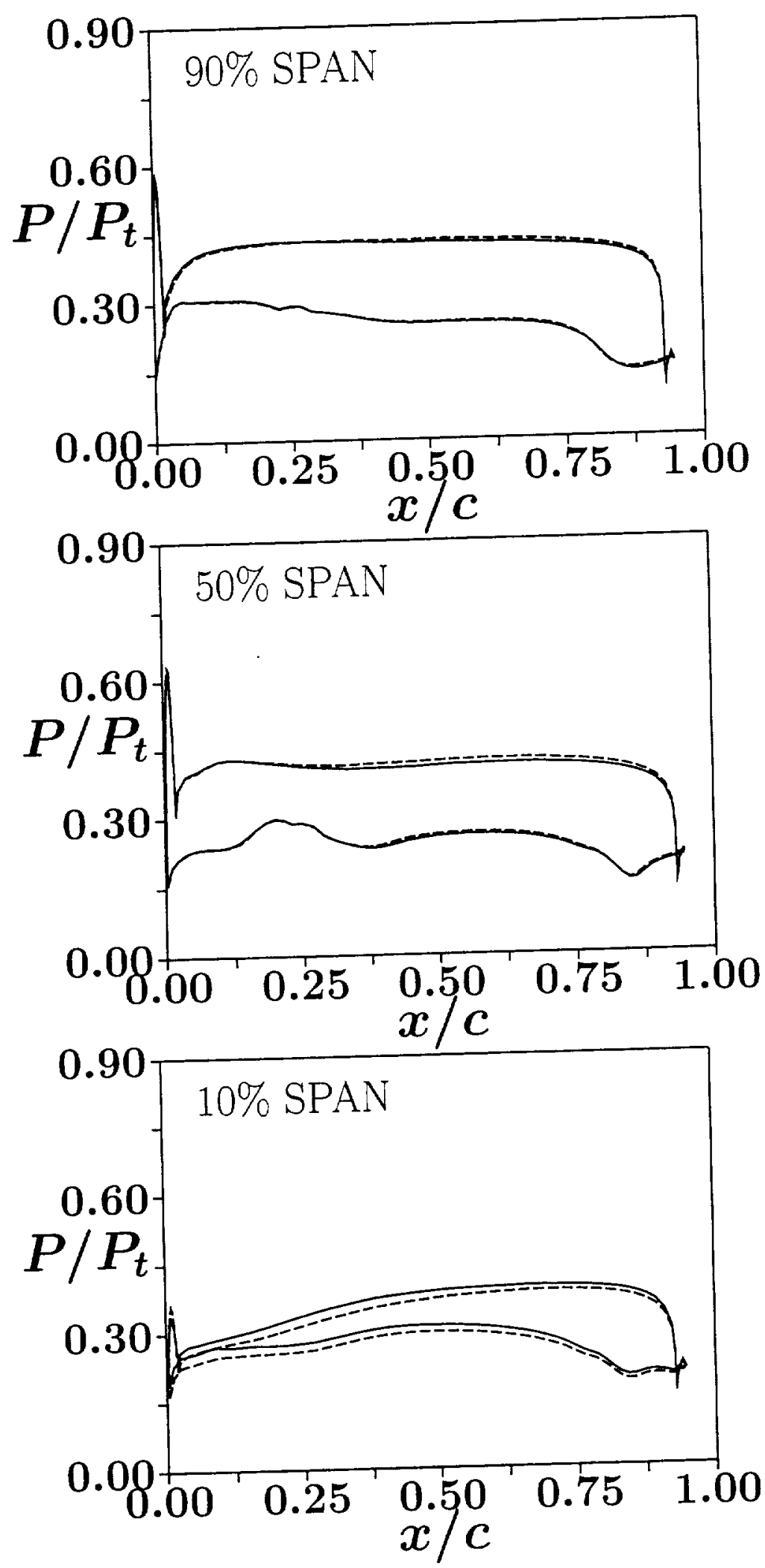

Figure 3: 


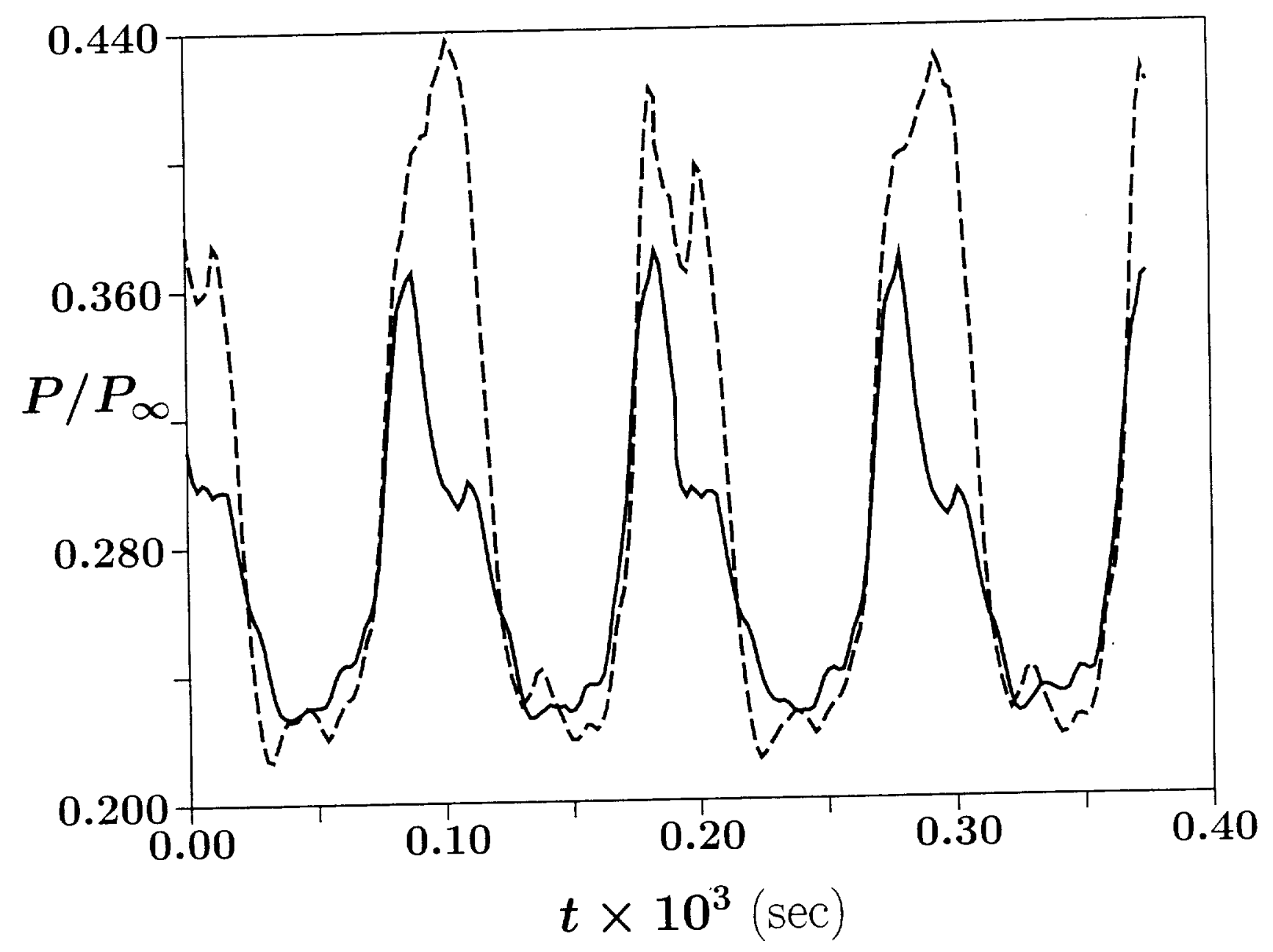

Figure 4: 


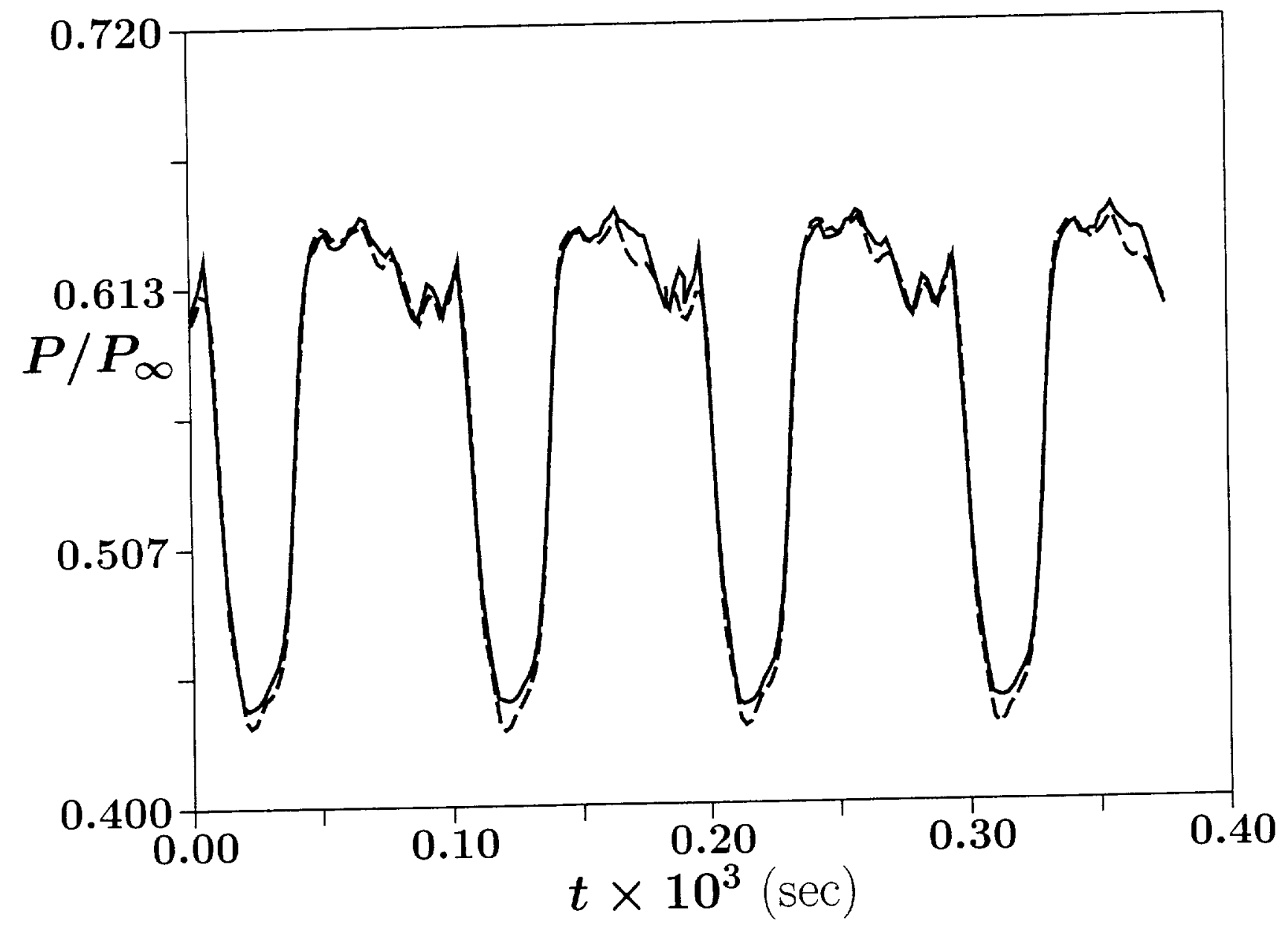

Figure 5: 


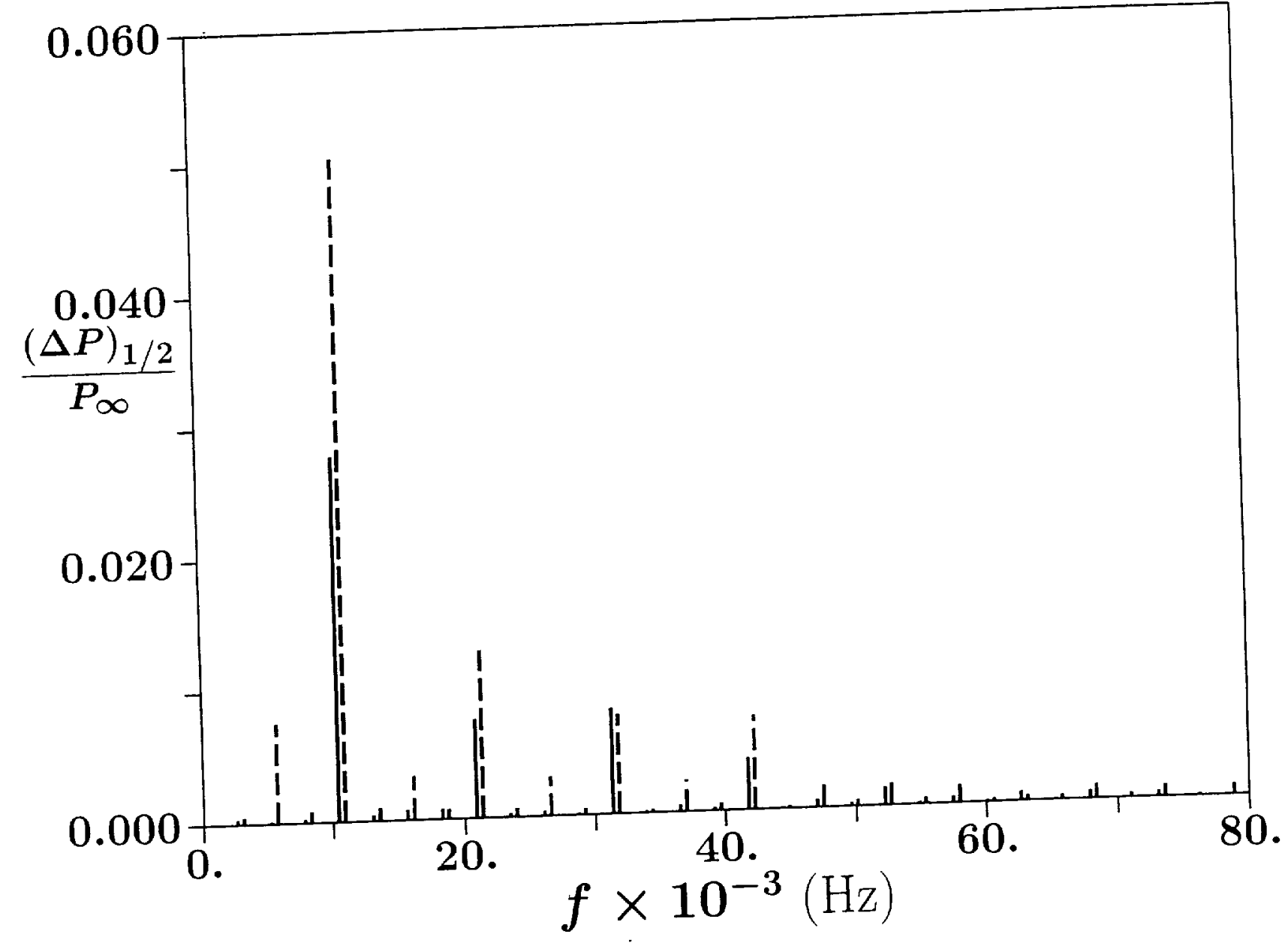

Figure 6: 